\title{
Historia oral: ¿una historia popular?
}

Is oral history a popular history?

Pedro Rodriguez Rojas

Doctor en Ciencias Económicas y Sociales y en Historia Docente e investigador de la Universidad Nacional Experimental Simón Rodríguez, UNESR, Venezuela pedrorodriguezrojas@gmail.com

Janette García Yépez

Doctora en Historia

Docente e investigadora de la Universidad Centro Occidental Lizandro Alvarado jgarciayepez@yahoo.es

Artículo de reflexión

Fecha de recepción: 12 de junio de 2013 • Fecha de aprobación: 23 de agosto de 2013

\section{RESUMEN}

El artículo empieza por reconocer la importancia de reivindicar una historia popular que revalorice el papel de los actores tradicionalmente excluidos —en oposición a la historia convencional de las élites-, por lo cual su propósito principal consiste en develar los intereses políticos que, bajo discursos populistas, sobredimensionan los testimonios orales para hacerlos pasar como equivalentes a la historia, en detrimento de las filosofías y teorías que, aun con sus deficiencias, han construido la cientificidad de la historiografía.

Palabras clave: historia de élites, historia popular, fuente oral, populismo.

\section{Abstract}

The article begins by recognizing the importance of claiming a popular history that enhances the role of the actors traditionally excluded, as opposed to conventional history of the elites. 
So that, its main purpose is to reveal the political interests that under populist speeches, exaggerate oral testimonies to pass them as equivalent to history, to the detriment of the philosophies and theories that even with its shortcomings, have built the scientific nature of historiography.

Keywords: History of elites, popular history, oral source, populism.

Todo conocimiento de la humanidad, sea de la naturaleza que sea, y se aplicara al tiempo que fuera, extraerá siempre de los testimonios de otros una gran parte de su sustancia.

Y así, las cosas de que habla la historia son las vicisitudes de la gente que cuenta, de los nobles, de los soberanos y de la burguesía, cuando llega a ser clase poderosa; en cambio los pobres, e incluso los aspectos de la vida que se consideran "bajos", no hacen historia.

Gianni Vattimo

Si la historia la escriben los que ganan, eso quiere decir que hay otra historia, la verdadera.

MignognA

Con frecuencia se dice que la historia la escriben los vencedores. También podría decirse que la olvidan los vencedores.

Peter Burke

El peor desconocimiento de la cultura oral quizá sea el que se produce en su pseudo-reconocimiento, como ocurre con frecuencia en los gestos de la política oficial. Jesús MARTín-BARBERo 


\section{Critica a la historia tradicional. REIVINDICADO LA HISTORIA POPULAR}

Conocemos las múltiples críticas que se le han hecho a la historia tradicional por representar fundamentalmente la historia de las élites. Como se repite, la historia la escriben quienes dominan, o por lo menos es la historia que más se conoce, la que se publica y la que se imparte en las escuelas a través de los textos oficiales. Esto no quiere decir que no hayan existido historias populares, de la insurgencia, contra la hegemónica, pero al igual que la cultura popular, se convierte en un acto de rebeldía y como tal muchas veces pasa clandestinamente. Hoy en muchas naciones se reivindican el papel del pueblo, de los humildes, los pobres, los excluidos, los trabajadores, los campesinos, las mujeres, lo que es ética y políticamente correcto.

Reconstruir la historia popular, no es tarea fácil, ya que la mayoría de fuentes documentales (protocolos, registros de escribanías, prensa) fueron no solamente redactados por un grupo élite sino que su intencionalidad era resguardar, preservar la acción, el accionar de estos grupos élites dominantes.

Eso ha sido nuestra historia, fundamentalmente política y militar, cargada de héroes, acciones bélicas, revoluciones, cambios de gobiernos. Asimismo la historia económica ha tenido como base las grandes propiedades, las familias y apellidos tradicionales, $y$ en la prensa se ven reflejados los grandes acontecimientos donde están involucradas las élites: desde los gobernantes, las grandes casonas, las haciendas, los clubes y centros de recreación, las manifestaciones culturales, reflejan el accionar económico, político y cultural de los sectores dominantes.

Esta configuración de las fuentes históricas es ya el primer inconveniente para construir una historia popular, difícilmente conseguiremos en documentos oficiales y en la prensa que se desarrollen con detalles la participación de los sectores populares. Estos poco o casi nunca aparecen reflejados en las guerras de independencia, las revoluciones políticas, y cuando lo refieren, normalmente, estas participaciones han sido catalogadas como: suburbios, "rebeldes sin causa", producto de "cuatro negros o indios realengos", cuando en realidad fueron motines que produjeron y exigieron un contingente militar 
de los gobiernos para enfrentarlos y con todas sus deficiencias y cualidades representaron una alternativa de trasformación.

En nuestra historia, tradicionalmente el pueblo se convierte en masa, en un colectivo sin forma, amorfo. Si es en el espacio político son "los soldados sin nombre" ni fama que acompañaron a los grandes héroes y caudillos. Si es en la actividad económica son los indios dedicados a los oficios domésticos y en los conucos, si son los negros solo aparecen como la mano de obra de las plantaciones, cuando se refieren a ellos normalmente se hace a través de las estadísticas para comprobar su peso en la economía. Cuando son estudios que abordan la dureza del trabajo, los maltratos del dueño o patrón, muchas veces se generaliza y no se entra en el detalle.

Lo mismo ocurre con la cultura de los pobres, llamada cultura popular, nombre que sirve para confundirlo con folklore y no se entra al fondo de lo que estas manifestaciones representan, como manifestación propia, particular, muchas veces signo de rebeldía, particular y concreta, y por tanto nada tiene que ver con popular como sinónimo de general, masificado y comercializado.

Difícilmente consigamos en la prensa latinoamericana del siglo XIX y principio del siglo XX que se narre la historia de las pulperías, no solo como actividad económica de los pobres sino como centro de recreación, conversación y hasta de organización política. Tampoco nos conseguimos con la historia de familias pobres, y cuando se habla de personajes populares casi siempre se hace para referirse a los enfermos mentales o aquellos cultores que son vistos peyorativamente.

A pesar de las críticas del debate posmoderno y todo lo que ha representado el "giro lingüístico" y los "nuevos paradigmas" que aparentemente confrontaban a los males del cientificismo, sin embargo existe aún hoy una marcada patología cientificista que reproduce lo peor del tan criticado y aparentemente derrotado positivismo. Cuando seguimos aferrados más a las técnicas y a los instrumentos que a la comprensión, la explicación de los procesos históricos, la cual no puede seguir siendo solo una narración apasionada e interesada del pasado, pero tampoco una simple recopilación de datos que por la antigüedad de los documentos y su amarillento color, parecieran automáticamente legitimar el trabajo del historiador y bendecirlo con el don de la 
verdad, cuando en realidad estos documentos fueron escritos por hombres de carne y hueso con una visión, unos intereses, que casi siempre coinciden con los intereses de las élites dominantes, que fueron las que auspiciaron a esos antiguos escribanos.

Tal como lo plantea Bermúdez y Rodríguez:

Con la oralidad la desconfianza procede, fundamentalmente, del temor, a veces exagerado, de los historiadores de confiar en la memoria que en algunas ocasiones se presenta escurridiza y fragmentaria, sobre todo en los informantes de más edad, y en la cual es difícil percibir la delgada línea que separa la verdad personal y el imaginario colectivo, los hechos reales del significado que estos adquieren para los entrevistados (la subjetividad del hablante), lo que podría afectar su credibilidad como fuente. Realmente este argumento no tiene sustentación válida porque lo mismo podría aplicarse a cualquier documento, cuyo contenido está mediado por la memoria, intención, motivación o interés de quien lo originó (2009, p. 320).

Ejemplo de ello lo encontramos en muchos documentos oficiales, particularmente los judiciales, que han sido escritos a partir de la declaración oral de testigos y luego convertidos en su transcripción a la jerga legal, con lo cual termina el testimonio original, ya tamizado por los condicionantes mencionados anteriormente, en una versión que ha sido manipulada por el abogado, juez o escribiente; sin embargo, estos documentos no pierden valor y siguen siendo empleados por los historiadores, siempre sometidos al proceso de crítica (validación) que se deriva de la aplicación del método histórico.

La historia del pueblo requiere de un esfuerzo mayor del historiador, que no puede ya conformarse con transcribir lo que las fuentes primarias le dicen o expresan directamente. Debe agudizar al máximo la capacidad de análisis y fundamentalmente de descubrimiento, en el encuentro de ese dato oculto, que no aparece explícitamente, que es subestimado por las fuentes, pero está allí reflejado, el historiador lo descubre.

Según González Boyero: 
Como afirma el propio Paul Thompson: "la historia oral es a la vez la forma más nueva y la más antigua de hacer historia”. Historia oral, es un término que Allans Nevins acuñó en los ańos cuarenta del siglo pasado para designar los testimonios de aquellos que han vivido un determinado periodo histórico.

La utilización de la historia oral nos lleva más allá de la esfera de lo público, sumergiéndonos en la historia de la familia, la historia social, la de la cotidianidad, sexualidad, relaciones interpersonales, la sexología, la religiosidad, las ideologías disidentes... en definitiva, todas aquellas áreas a las que no se pueden acceder simplemente con los documentos escritos. Podemos afirmar que la historia oral es la única forma de historia en la que es posible interrogar a los protagonistas de la misma cara a cara, y prestar atención a grupos marginados de la sociedad que han permanecido ocultados a la historia tradicionalmente (2012).

Las fuentes orales en la historia nos permiten: 1) La reconstrucción histórica de un pasado cercano, próximo. 2) Abordar temas marginados por la historia tradicional. 3) Fortalecer lazos intergeneracionales y comunitarios, entre miembros de distintitas generaciones y con los vecinos. 4. Revalorizar el papel que en las comunidades tienen los sujetos en estudios (mayores, deportistas, cultores, maestros, comerciantes, etc.). 4) En términos pedagógicos -sobre todo pensando en los aprendices-, el investigador se siente más motivado y comprometido estudiando un tema que le es más familiar, más sensible y de mayor utilidad a su comunidad. 5) Se convierte además en un ejercicio de tolerancia hacia las ideas y el accionar de los otros.

Es necesario enfrentar a la supuesta objetividad del método histórico, rescatar el papel de la narrativa y la creatividad del autor que ha sido sustituido por supuestas técnicas frías de observación que sustituyen "al creador por el operador", convirtiendo al historiador en un fotocopiador de documentos y archivador de fichas y hoy en expertos operadores de computadores. El tecnócrata sustituye al creador, al filósofo. Es necesario rescatar al historiador humano, al historiador ético, al que dialoga con los documentos y con los otros hombres, contra el monólogo del historiador-dictador que por la fuerza le dice al pasado qué hacer. 
La pretensión objetivista y cientificista es quizás uno de los peores males que como herencia del positivismo aún cargamos a cuestas, y que ha hecho perder el verdadero sentido de la práctica historiográfica que es tratar de restablecer la relación entre presente y pasado, darle sentido al tiempo histórico, no solo en la perspectiva contemplativa o de erudición de la que tradicionalmente hacen gala los autodenominados historiadores.

Ante la pretensión de un pensamiento único, es urgente la reconstrucción de una nueva historiografía sin pretensiones universalistas y hegemónicas, que no sea lineal ni mesiánica, que le dé sentido a la lucha de los que históricamente han sido excluidos y cuyas causas de exclusión solo se encuentran en el proceso histórico. Una historia de lo rural, de los negros, de los perseguidos, de las rebeliones, de las mujeres, de los niños, de los presos, en fin, una historia de los pobres, de los oprimidos, de las víctimas.

Por lo anteriormente señalado, nos enfrentamos a una historiografía cientificista, descriptiva, vacía de fundamentos teóricos y filosóficos que solo ha servido para legitimar a los opresores del pasado y del presente, ante lo cual apostamos por una historia comprometida, una historia del pueblo, de los oprimidos, de las víctimas, una historia que asume posición frente a un mundo injusto, desigual, una historia política, no en el sentido partidista ni mucho menos en el sentido romántico solo pasional del pasado, sino en el sentido de compromiso. "Una "politización", en el sentido de la autorreflexión de las ciencias no es solo legítima, sino que representa también la condición de una autonomía de la ciencia que ya no puede preservarse hoy apolíticamente" (Habermas, 1990, pp. 358-359).

Entre las tareas prioritarias de esta historia nos atrevemos a proponer las siguientes: 1) Desmontar el discurso de la historiografía dominante: desde la tradicional eurocéntrica y hegemónica, pasando por la nacionalista romántica e incluyendo una supuesta historia marxista revolucionaria, que margina la subjetividad y lo cultural y sobre todo margina el pueblo a favor de una supuesta vanguardia. 2) Lo más importante, desmontar la estructura de la dependencia intelectual, de la estructura cognitiva con la que hemos sido formados, que no nos permite vernos a nosotros mismos sino solo a través de los ojos de los otros, que subestima nuestra propia producción intelectual y que nos hace siempre buscar y casi endiosar a teóricos y filósofos provenientes de los centros hegemónicos. Sin pretensiones chauvinistas es necesario construir nuestra 
historia con nuestras categorías, nuestras teorías, es decir nuestros intereses. 3) Frente a la imposición de un pensamiento único globalizador es necesario sustentar un pensamiento disidente que sirva de base para la organización de los excluidos. 4) En definitiva, es necesario tomar posición, no es tiempo para vacilaciones ni para posturas moderadas. O formamos parte de una historia conservadora, legitimadora de la opresión o por el contrario de una historia crítica y comprometida.

\section{RECONOCIMIENTO DEL SABER POPULAR}

El primer compromiso de esta historia popular, no es conformarse con recrearse en lo anecdótico, con lo que siempre se confunde o mejor dicho se manipula con el concepto "popular", no solo como símbolo del pasado o símbolo cultural, sino vincular estos saberes con sus "dueños", los hombres de carne y hueso que lo han producido. No es un saber mercancía que se compra y vende en las ferias artesanales. Nos interesa su análisis social, su ubicación contextual, en las relaciones de poder, en una clase social determinada, su papel de excluidos y de víctimas de un sistema.

Diferenciamos el saber popular con la simbología a la que ha sido cercenado este concepto: delimitándolo a las expresiones artísticas, lo que no deja de ser cierto pero es insuficiente ya que no aborda la naturaleza vivencial de los actores, los seres humanos que lo producen: indígenas, afrodescendientes, campesinos, pobres, excluidos y víctimas de un sistema social que históricamente los ha sometido. Sin embargo, a través de sus manifestaciones artísticas y junto a su forma de organización y experiencias de trabajo, del cómo han abordado los problemas de salud, vivienda, recreación han creado brecha en el sistema que los somete.

También está la concepción del saber popular que lo cataloga de retrograda, ignorante, común, vulgar, charlatanería, brujería. En el fondo lo que se subestima o se pretende controlar es al pueblo que lo produce, eliminando o apropiándose de su cultura y su organización socioeconómica. El saber popular puede y debe ser tomado en cuenta para un proyecto de sociedad distinta, en donde se reconozca y dignifique a estos seres humanos, que son la mayoría. 
Es necesario rescatar el saber popular de ese conocimiento práctico que es producto de la experiencia, de las tradiciones, herencia de las culturas que nos antecedieron, pero que tienen la capacidad de dar respuestas a su contexto, que rompe con el razonamiento frío y calculado, que es más libre, menos dogmático, que ejerce una ética permanente de respecto al otro y a la naturaleza.

El pensamiento de todos los seres humanos que hizo posible su sobrevivencia le fue despojado, arrebatado, para imponer un tipo de conducta, un modo de vida homogenizarte, que favorece el mantenimiento de estatus quo. Esto es lo que Marx llamó la alienación. Pero esta realidad, que en parte es cierta e innegable, tampoco puede ocultar o ignorar eso que llamamos saber popular que en buena parte es el que ha hecho posible una especie de socialismo rudimentario o espontáneo, que ha permitido a través de formas de trabajos de organización y de cooperación la sobrevivencia de estas poblaciones. En los barrios, en el campo, hay formas de organización social que históricamente han garantizado la subsistencia de esta población, pero también han abierto una brecha importante en el modelo de mercado capitalista, predominante en las grandes urbes.

A este respecto, uno de los términos que requiere una reformulación urgente es el de lo “popular”, con lo cual se pretende hablar en nombre de las mayorías sin distinción de status social, económico, étnico y cultural: "lo popular es en esta historia lo excluido: los que no tienen patrimonio, o no logran que sean reconocidos y conservados" (García Canclini, 1990, p. 230).

Autores como Vargas (1999), insisten en este sentido de lo "popular" como manifestación de la resistencia y cuestionamiento a la cultura dominante: "ello quiere decir que el símbolo popular, el producido por la gente como parte de su discurso escondido de resistencia, no solo se hace abierto y público sino que pierde su carácter cuestionador y subversivo" (p. 153).

La omnipotencia del conocimiento científico ha subestimado a los conocimientos de origen mucho más antiguo: al conocimiento cotidiano, que es numéricamente superior e imposible de ser sustituido. Pero también hay un cuestionamiento del pensamiento lineal de aquel que se supone es producto de un proceso: el paso obligatorio por 
sucesivas etapas cognoscitivas. Asimismo, se cuestiona la razón occidental que pretende explicar al mundo partiendo de un punto de vista intrínsecamente dependiente del modo de vida de las civilizaciones occidentales, que subestima o ignora al resto de las civilizaciones.

En su obra El conocimiento ordinario, Michel Mafesoli (1993) dedica amplio espacio a refutar esta omnipotencia del conocimiento científico y de la racionalidad lineal, a la idea de que solo la razón nos permite entender y comprender el mundo. No se trata de llamar al irracionalismo, tan reduccionista como el racionalismo puro, sino de entender que el pensamiento humano se compone de ambos y de otras cosas:

Existen, en efecto, dos obstáculos que con regularidad surgen en el orden del pensamiento y de la acción social: el racionalismo y el irracionalismo. Como si se tratara de una pareja perversa, interactúa el uno con el otro, se llaman, se complementan, se cortejan y no puede de ningún modo prescindir el uno del otro (p. 37). (...) Acaso hay que considerar que nuestro conocimiento del mundo es una mezcla de rigor y de poesía, de razón y de pasión, de lógica y de mitología (p. 66).

No existe saber académico sin una sustentación a partir de un conocimiento o un saber popular. Al decir de Paulo Freire (1977), “de ahí que no haya ignorancia absoluta ni sabiduría absoluta”.

Pero no deseamos ni podemos caer en contradicciones ya que creemos que existe una falsa conciencia o alienación que ha hecho que la mayoría no tome conciencia de las causas profundas de sus condiciones de vida (explotación, dominio ideológico de la religión y de los medios de comunicación), y la posible y necesaria transformación social.

Pero tampoco es menos cierto que en la mayoría de los casos la educación formal, el mensaje y el discurso religioso, político, y de los medios de información nos han adoctrinado en el pensamiento capitalista que legitima la desigualdad a favor de unos pocos. Según Valderrama: 
Si una sociedad está sometida al control económico, político, militar de un sector, que domina al resto, justo es pensar que ejerza también un control ideológico, que se traduce en una estructura psíquica, en una moral, en una cultura, que juntos conforman un poderoso sistema de dominación (2000, pp. 26-27).

Consideramos importante el aporte de los estudios culturales: las mentalidades, las particularidades étnicas, el multiculturalismo, como revalorizador de la diversidad humana y el llamado respeto y el reconocimiento a los otros, como legítimos otros. Pero consideramos que esta perspectiva no es suficiente, ya que muy poco toca u obvia las estructuras del poder económico, cultural y político a nivel nacional y mundial, que desde las grandes corporaciones trasnacionales, el imperialismo en sus viejas y nuevas modalidades de intervención, el poder mediático y frente a los organismos internacionales como la ONU, el FMI, supuestamente llamados a garantizar la paz y el equilibrio económico mundial, pero que en realidad solo representan los intereses de las grandes potencias, el multiculturalismo no solo no es suficiente sino que por el contrario puede convertirse -la mayoría de los casos sin quererlo- en presa fácil de quienes históricamente nos han dividido.

Asumimos una posición radicalmente crítica y enfrentada a quienes en nombre de las ciencias y de una aparente objetividad desarrollan un discurso indeterminado, donde no pareciera existir seres humanos que hablan en nombre de aquellos, estos, ellos, es decir; conceptos deshumanizantes que convierten al hombre en cosas, lo cosifican. Donde no existe compromiso, se evitan las emociones. Esta aparente neutralidad en realidad es legitimadora de un mundo deshumanizante, materialista, en donde el lenguaje sirve para enmascarar el poder. El "Yo", el "Tu”, el "Otro", el "Nosotros”, están cargados de naturaleza humana, ellos representan posiciones, intereses, emociones, por lo tanto son inherentes al discurso del hombre, sea este poético, narrativo o científico.

Levinas (2002) en su obra Algunas reflexiones sobre las filosofías del hitlerismo es categórico al señalar: "la ciencia, la moral, la estética, no son moral, ciencia ni estética en sí, sino que traducen a cada momento la posición fundamental de las civilizaciones burguesas y proletarias" (p. 12). 
Para el filósofo argentino Enrique Dussel (2001): "dicho reconocimiento del discurso del otro, de las victimas oprimidas y excluidas, es ya el primer momento del proceso ético de la liberación, "de la filosofía" (p. 76).

En Pedagogía de los oprimidos, Paulo Freire (1991) es más categórico al señalar que la investigación social no se hace en forma unidireccional sobre los otros sino con los otros: "solo existe saber en la invención, en la reinvención, en la búsqueda inquieta, impaciente y permanente que los hombres realizan en el mundo, con el mundo y con los otros" (p. 73). "La investigación del pensar del pueblo no puede ser hecha sin el pueblo, sino con él, como sujeto de su pensamiento” (p. 30).

Orlando Fals Borda (1992, p. 47), uno de los más importantes representantes de la Investigación Acción Participativa, insiste en "que unos de los problemas centrales a aclarar en la metodología de la investigación-acción para el cambio radical es el de la producción del conocimiento científico". Este autor habla de ciencias emergentes o subversivas y ciencia popular para referirse a "aquel conocimiento que les ha permitido crear, trabajar e interpretar predominantemente con los recursos directos que la naturaleza ofrece al hombre" (p. 48). Borda parte de "la filosofía espontánea" y del "intelectual orgánico" al que hizo referencia Gransci. Asimismo de Foucault toma su "historia viva" en la "arqueología del saber" para rescatar la sabiduría popular, aquella que ha hecho posible sobrevivir económica y culturalmente a una gran mayoría marginada de los bienes de producción y de consumo.

En respuesta a los que muchos críticos han señalado al ver esta corriente como ingenua, Borda es consciente de lo delicado que es hablar de una ciencia del pueblo, o más aún ciencia de proletariado, señalando que este es un dogmatismo político que además de anticientífico poco contribuye con las verdaderas causas populares, ya que su construcción es impuesta de manera paternalista y sirve más para el control que para la liberación. La propuesta de Borda y quienes lo acompañan es el que sea la comunidad la que construya su propia ciencia, donde no se niegue el papel del académico tradicional, pero este nunca se podrá convertir en un mediador de la investigación, es un acompañante. 
Términos como concientización, diálogo, compromiso y acompañamiento son propios de este tipo de investigación, que no persigue el control ni de conductas ni de seres humanos, como lo hacen la mayorías de investigaciones científicas, sino la deconstrucción del pensamiento hegemónico dominante y su sustitución por un pensamiento liberador, donde el conocimiento sea para entenderse y relacionarse con los otros y no para dominar. Este es un tipo de investigación claramente comprometido política e ideológicamente con un proceso de transformación de la formación social y económica capitalista dominante.

Compartimos con Nélida Landreani cuando advierte sobre las desviaciones de estas nuevas propuestas investigativas:

Una apreciación ligera acerca del uso de la Investigación Participativa ha llevado a un descuido metodológico que redunda en una falta de rigor científico de las mismas, y justifica en parte ser caracterizadas como prácticas panfletarias, desacreditadas por su proyección política” (1990, p. 23).

Para Mafesoli (1993) se trata de que lo que "es" tiene prioridad sobre lo que "debe ser". Pero advierte nuevamente que no se trata de caer al extremo de una idolatría de lo cotidiano o popular:

Habrá que volver a tratar este punto con más precisión, aunque seguramente el surgimiento del método llamado "historias de vidas", cuando no cae en las costumbres cuentistas, se propone responder al sentimiento de impotencia... (p. 153). (...) Así pues, ya no se trata de "corte" o "ruptura" epistemológica ni de distancia crítica, sino más bien de una comprehensión del presente popular (que se encuentra en la redundancia y la teatralidad) mediante variaciones intelectuales que no demuestran, sino que expresan. (...) Ahora bien, la vida cotidiana es rutilante y polisémica, hecha de luces y sombras; en una palabra (lo que cada vez es más aceptado), es obra de un hombre a la vez sapiens y demens (p. 156). 


\section{ADVERTENCIA: MAGNIFICACIÓN Y MANIPULACIÓN DE LO POPULAR}

Debemos advertir de los peligros de una pretendida historia popular que en muchos casos más que una historia científica (con argumentos y uso riguroso de las fuentes), se convierte en una historia estrictamente ideológica, cargada de buenas intenciones pero con muy poco rigor y carácter científico.

Primero, debemos aclarar que no todo lo que llamamos fuente oral en la ciencia de la historia, lo es. Segundo, que no hay una historia oral sino una metodología y fuentes orales. El uso de las fuentes orales en la ciencia de la historia tiene todo unos criterios, no es simplemente hacer preguntas a unas personas, no es una simple biografía ni conversación, por más amena que sea.

La fuente oral se ha convertido en un valioso instrumento y forma parte de una nueva metodología para reconstruir la historia, busca "hacer hablar a los que no han tenido voz", a los que han sido silenciados de nuestra historia. Pero haciendo este reconocimiento debemos estar conscientes de que no existe una historia oral, es una técnica metodológica, paradigmáticamente y políticamente puede servir y ser usada por igual por positivistas y teóricos críticos, por corrientes conservadoras o progresistas. No puede haber una reconstrucción histórica basada solamente en fuentes orales. Por más rigurosa que sea la metodología, por más claridad filosófica y argumentos teóricos que tenga el historiador la fuente oral no es suficiente, aunque sea para la historia popular condición indispensable.

Así lo advierte Ronald Fraser:

Como reconoce el mismo Hobsbawn, esta forma de Historia Oral puede dar como resultado libros apasionantes, pero no libros de Historia. Necesitamos saber, como él dice, no solo qué pasó, sino por qué pasó. Antes de entrar en el tema creo que sería útil detenernos un momento para considerar el término Historia Oral. Este término se presta a confusión porque parece que quiere ser una disciplina distinta, como la Historia Económica, cuando de hecho es una técnica para la investigación histórica (1993, p. 79). 
La historia popular tiene en la fuente oral un elemento primordial. Pero no podemos confundir historia popular con historia oral. Las fuentes orales también pueden servir para reconstruir la historia de las elites. Pero lo más importante es afirmar que sin la triangulación con las fuentes documentales primarias y secundarias la llamada historia oral se convierte en relato, en narración política, mitológica, útil para el análisis lingüístico y del discurso, pero no es historia.

A un nivel práctico, hay algo que une a todos los que utilizan fuentes orales, y eso es el saber que estas fuentes no bastan por sí mismas. Todos están de acuerdo que hay una labor anterior imprescindible, que es la de cualquier historiador o investigador: la consulta obligatoria de todas las otras fuentes primarias y secundarias que pueden tener relación con su campo de investigación (Ibídem, p. 92).

Debemos advertir sobre la magnificación de la fuente oral. En el caso de Venezuela, en el contexto del proceso revolucionario encabezado por el presidente Hugo Chávez desde 1999, se ha iniciado una política de reivindicación de los excluidos, no solamente otorgándole poder económico y político, sino reconociendo su papel en la historia. Desde el discurso presidencial, pasando por los programas de estudios de las nuevas universidades, La Misión Cultura y las otras misiones educativas, el Centro Nacional de Historia y los nuevos medios de comunicación han hecho todo un esfuerzo por rescatar y reconocer el papel del saber popular y toda la historia de la mayoría de la población que fue sometida, no solo económicamente y políticamente sino marginados de la historia.

Con esta intencionalidad estamos totalmente de acuerdo, nuestras diferencias comienzan en el plano metodológico. Lamentablemente muchos de los actores que pretenden convertirse en investigadores e historiadores de lo popular no cuentan con las herramientas teóricas y metodológicas para lograr este fin. No han sido formados para diferenciar entre lo que es una entrevista y una narración con lo que es la construcción histórica.

La fuente oral magnificada puede caer en el error de hacer de una historia individual, una biografía, una narración particular, convertirla en un hecho único, cuando a lo 
mejor no lo es. Se cae fácilmente en el individualismo, la magnificación de los personajes populares, lo que sería una historia al revés, pasando de una historia de los grandes héroes de las elites a una historia de los personajes e individualidades populares. $\mathrm{Al}$ final seguirían siendo historias individuales, donde se pierde el sentido del colectivo, en este caso, del pueblo. Tampoco toda historia oral o testimonio puede ser identificado como sinónimo de historia popular, no obligatoriamente refleja actos de rebeldía, ni el testimonio es siempre una denuncia. Muchas veces la fuente oral, que tiene como objeto a personajes populares, nos ofrece evidentes grados de alienación y complicidad con los sectores dominantes.

La llamada historia oral muchas veces es el pretexto para hacer una historia de las victimas, como si se tratara de una narración mitológica o simplemente el drama de una película: la lucha entre el bien y el mal, entre lo bueno y lo malo, entre las victimas y los victimarios, donde los pobres siempre son las victimas y no son responsables ni culpables en nada de su situación. Todo es justificado como el producto de la dominación, de la explotación económica y de la alienación política y cultural. Al decir de Hobsbawm: "los historiadores profesionales son los principales productores de la materia prima que se transforma en propaganda y mitología” (1998, p. 14).

Así como existe en el mundo político una vanguardia o partido que reivindica lo popular, también debe existir una historia popular que le dé heroicidad. Esto es una historia manipulada, una historia política, que más que histórica es política, se trata de buscar simpatía, vía populismo. Esto hace que desde la noche a la mañana comiencen a surgir desde etnias indígenas, culturas ancestrales, movimientos afroascendentes, levantamientos políticos, protagonismo en la guerra de la independencia, magnificación de movimientos rebeldes y guerrilleros, pero que no tienen sustentación en ninguna otra fuente, salvo en la imaginación humana. Eso no es historia.

Para Peter Burke:

Un mito recurrente (que encontramos de muchas formas en nuestra propia sociedad) es el de los "padres fundadores"; la historia de Lutero como fundador de la Iglesia protestante, de Émile Durkheim (o Max Weber) como fundador de la sociología, etc. En términos generales, lo que ocurre en el caso 
de esos mitos es que se eluden las diferencias entre el pasado y el presente, y las consecuencias no intencionales se convierten en objetivos conscientes, como si el principal propósito de estos héroes del pasado hubiera sido producir el presente, nuestro presente (2000, p. 207).

Quizás todo esto se lo debemos a eso que Marc Bloch llamó los placeres estéticos de la historia y su capacidad seductora, que hace que -a diferencia de otras disciplinas científicas- surjan a granel "historias" y leyendas, e "historiadores populares" en todas las esquinas, quienes dicen verdades y mentiras en la misma proporción, y por su "popularidad" y sencillez gozan de más afecto que los historiados verdaderos:

La historia, sin embargo, tiene indudablemente sus propios placeres estéticos, que no se parecen a los de ninguna otra disciplina. Ellos se deben a que el espectáculo de las actividades humanas, que forma su objeto particular, está hecho, más que otro cualquiera, para seducir la imaginación de los hombres (1981, p. 44).

En este punto, no hay mejor referencia que Eric Hobsbawm, quien llama a la responsabilidad del historiador para establecer la diferencia entre realidad y ficción, para enfrentar los anacronismos de querer "buscar los deseos del presente en el pasado", para satisfacer a los que desde el presente pretenden construir un pasado "a la carta".

Para Hobsbawm, la deconstrucción de mitos políticos o sociales disfrazados de historia, forman parte desde hace tiempo de las obligaciones profesionales del historiador, con independencia de sus simpatías. Pero no es tarea fácil, cuando:

En primer lugar, la fuerza de su crítica es negativa. (...) En segundo lugar, podemos demoler un mito solo en la medida en que se apoye en proposiciones cuyo carácter erróneo pueda demostrarse. Es muy propio de los mitos históricos, en especial de los nacionalistas, que generalmente solo unas cuantas de sus proposiciones puedan desacreditarse de este modo (pp. 9-10). La tercera limitación de la función del historiador como matador de mitos es aún más obvia. A la corta, es impotente contra quienes optan por creer los mitos históricos, en especial si se trata de gente que tiene poder político, lo cual, 
en muchos países, y especialmente en los numerosos estados nuevos, entraña el control de lo que sigue siendo el cauce más importante para impartir información histórica: las escuelas. Y, que no se olvide jamás, la historia -principalmente la historia nacional-ocupa un lugar importante en todos los sistemas conocidos de educación pública (1998, p. 11).

Las últimas décadas del siglo XIX han sido denominadas provocadoramente por Eric Hobsbawm como la era de "la invención de la tradición": el objetivo era esencialmente justificar o "legitimar" la existencia de la nación (p. 79-80).

No se trata de reivindicar las corrientes positivistas y el papel de las fuentes escritas. Pero es necesario señalar que con toda la intencionalidad de estas fuentes y el reconocimiento de que son productos de los intereses de las élites dominantes, la mayoría de los casos no responden a caprichos, la mayoría de estas fuentes responden a obligaciones: desde escribir un suceso o un hecho, rendir un informe, tenían como destino contribuir con el control económico político y cultural, y aunque en el análisis del lenguaje consigamos parcialidades y elementos de subestimación a los dominados, debían evitar el invento, la magnificación innecesaria, porque ese discurso era y es aún hoy un elemento administrativo del control de las élites.

La fuente oral, sin negar sus méritos, se enfrenta con el peligro del poder de la memoria: 1) ¿Qué tanto, cuánto y desde cuándo puedo recordar con precisión? 2) ¿Cuándo puedo diferenciar lo que es verdad de los que es imaginación? 3) El sujeto a investigar o entrevistado es un hombre como todos lleno de pasiones, que narra sus propias visiones de los hechos y que por lo tanto se parcializa si él o uno de los suyos estuvo involucrado en el suceso a investigar. 4) La manipulación del investigador, transcribir lo que le conviene o no.

Así como no puedo magnificar a la fuente oral y darla como verdadera, tampoco lo podemos hacer con la historia popular. Ya el hecho de hablar de historia de las élites y de historia popular es una parcialidad, es una pretensión que está cargada de subjetividad y de intencionalidad política. 


\section{Desviaciones Metodológicas}

Han sido evidentes los errores reconocidos a la investigación cuantitativa, en general: el objetivismo, la pretendida o añorada objetividad del investigador, la desvalorización del contexto socio-cultural, el no tomar en cuenta las emociones y particularidades de los sujetos, la verticalidad y el carácter monológico que pretenden ver la realidad como una condición estática que puede ser medible y controlable. Por el contrario, las investigaciones de orden cualitativo se presentan como un reconocimiento a la relatividad de la ciencia, a la inexistencia de las verdades absolutas, a la revalorización del contexto, la cultura, la subjetividad, a la horizontalidad de la investigación y al carácter dialógico, en donde objeto y sujeto forman parte de una misma realidad, no están separados. Se pretende romper con las ataduras de los rituales metodológicos, haciendo más importante la esencia del conocimiento, su sentido que la rigurosidad de los procedimientos utilizados. Frente a esta discusión así planteada es difícil no tomar parte a favor de lo cualitativo. Sin embargo, es precisamente advertir sobre posibles riesgos en los que pudiera caer esta perspectiva de investigación cualitativa en la historia.

\section{1-Reduccionismo}

Considero que esta discusión de lo cualitativo vs. lo cuantitativo y la correspondiente parcialización hacia lo primero sobre lo segundo, pudiera caer en el mismo reduccionismo que tanto se le ha criticado a la investigación cuantitativa por tomar en cuenta solo la realidad medible y verificable y los documentos como fuente primordial. Hoy todo lo que tenga que ver con el paradigma positivista produce una reacción adversa, nadie quiere que lo tilden de conductivista y mucho se cuidan de hacer uso del método hipotético deductivo y de las categorías propias del positivismo: objetividad, comprobación, explicación. Por el contrario hoy "todos somos cualitativos", constructivistas, hermenéuticos, etnográficos, no importa si al final nuestras investigaciones, después de un largo discurso cualitativo, terminamos hablando de datos, muestras, instrumentos, variables, experimentos, objetividad, validez y verdad.

Este reduccionismo es, a mi modo de ver, más un "modismo intelectual", que una perspectiva ontoespistemológica. Lo cualitativo pudiera estar sirviendo, entre otras cosas, para marginar lo cuantitativo, no solo por la críticas que siempre se le han hecho 
por su insuficiencia para explicar la realidad, sino por el desconocimiento y en algunos casos hasta la fobia que muchos científicos sociales le tienen a lo quántico. Pero lo más importante es que este reduccionismo ignora y margina la historia de la ciencia, esa ciencia que tiene en el positivismo su partida de nacimiento. Asimismo ignora que el pretendido rescate de la subjetividad no puede hacerse obviando una parte de la realidad que es física y que puede ser medible, que existe una realidad natural-material y no está determinada por nuestras emociones y deseos. Concretamente en la ciencia de la historia, cómo negar el papel histórico del positivismo como madre de esta ciencia y que hoy por mucha aversión que produzca con solo mencionarlo, sigue teniendo espacio y vigencia.

\section{2- La pretendida neutralidad y objetividad del investigador participante}

Bajo el enfrentamiento a la tradicional perspectiva epistemológica que separa al objeto y sujeto de investigación, la investigación cualitativa señala que el investigador debe abordar la realidad a estudiar como un participante más, sin prejuicios. Consideramos que esto es nuevamente una contradicción que por un lado niega la formación cultural y científica del investigador, es decir, niega la subjetividad contradictoriamente revalorizada por lo cualitativo. Supuestamente el investigador en un proceso dialógicohorizontal se convierte en mediador y no en interventor. El investigador siempre será el investigador, y aunque dure años inmerso en la sociedad que estudia, siempre la estará percibiendo como un objeto de estudio, de lo contrario hará trabajo comunitario, servicios sociales, pero no ciencia. Pero si la comunidad no es la original del investigador, aunque viva allí durante largo tiempo no podrá ser un miembro más de esa comunidad, ya que no ha pasado por el proceso de socialización de los otros miembros y estos siempre lo verán como el investigador, el extraño. Desde lo cualitativo no podemos hablar de verdades absolutas, objetividad y neutralidad, la validez está en su coherencia paradigmática, en la profundidad de los argumentos teóricos y los procedimientos expuestos a la contrastación y su valorización ético-político.

\section{3- Primacía del método sobre lo teórico}

Una de las principales críticas que se le ha hecho a los historiadores tradicionales es sobre la valorización del método (primacía de las técnicas y los procedimientos), sobre 
la significación y utilidad misma de la investigación. Sin embargo las ataduras y rituales metodológicos tan cuestionados no han llegado a su fin. Para muchos investigadores cualitativos la investigación debe comenzar es por el método y lo teórico será un producto de este, una construcción con los otros sujetos o comunidad donde se realiza la investigación.

Esta posición pretende negar la realidad de que, aunque la teoría no esté explícitamente desarrollada, ningún investigador hace investigación sin asumir posiciones teóricas $\mathrm{y}$ ontoepistemológicas, aunque sea tácitamente, la pura escogencia de un tema $\mathrm{u}$ objeto de estudio ya manifiesta una percepción de lo real, que puede ser cambiada o transformada en el proceso investigativo, pero existe previamente. Compartimos con Martínez Miguelles (1999) quien señala: “...es necesario aclararlo de manera explícita al desarrollar los capítulos referidos al paradigma epistemológico y al marco teórico, que deben preceder a toda investigación cualitativa y etnográfica respetable” (p. 40).

Algunos investigadores proponen que al privilegiar el método sin los prejuicios de la teoría pudiera garantizarse un mayor acercamiento a la verdad. La investigación ahora es amoldada al método, el cual viene predeterminado por la autoridad del historiador y la "autoridad científica" de los metodólogos. A nuestro modo de ver esto puede tener como causa: 1) ignorancia o debilidad ontoespistemológica del historiador, 2) pragmatismo, donde lo importante es resolver problemas más que comprender realidades, 3) una mal entendida liberación del pensamiento y un anarquismo que cae en el facilismo y lo ecléctico.

En el fondo en esta posición nuevamente nos conseguimos con la patología científica en la búsqueda de la objetividad y la neutralidad del investigador, el pretender "investigar investigando con los demás", no puede negar el papel de la teoría, que es negar en cierta forma la historia de la ciencia, porque investigar sin teoría previa se puede caer en el error de estudiar temas hartamente tratados y por lo tanto sin sentido.

\section{4- Idealización o sobrevaloración del objeto y sujeto de estudio}

En la mayoría de estas investigaciones, fundamentalmente las llamadas etnográficas, ante la marginalización de la teoría y la historia de la ciencia, se asume una idealización 
o sobrevaloración del objeto de estudio, donde el saber no está en los documentos sino en la "esencia misma del pueblo". La mayoría de investigadores en estas áreas están ligados a la antropología cultural y algunos aparentemente marxistas hablan del saber popular y la verdad del pueblo enfrentados al saber filosófico y al conocimiento científico, y por ende responden más a principios de orden político-ideológico que a principios científicos. Su objetivo es contribuir al bienestar social, para lo cual la ciencia puede ser o no un camino, pero no el único, y esa posición es válida. El cuestionamiento que hacemos es que cuando al privilegiar los principios políticos sobre los científicos, se hace del saber popular un fetiche: "el pueblo tiene la razón", "el pueblo no se equivoca".

Esta pretendida ciencia popular ignora el tratamiento marxista sobre la alienación o falsa conciencia según la cual en los niveles ideológicos políticos y culturales de la mayoría de la población, ajena a la propiedad de los medios de producción, se reproducen la concepción ideológica, política y cultural de la elite dominante, y si bien epistemológicamente es válido hacer uso de los conceptos y categorías utilizados por el pensamiento común, mítico y religioso, desde la ciencia y la filosofía están en la obligación de prevenir sobre las trampas y obstáculos epistemológicos de este lenguaje. Cuesta reconocer que la mayoría de estos seres a los que llamamos pueblo (categoría ambigua que nada define, salvo en su concepción geográfica) no ha sido formada para la participación activa sino para seguir a un líder o una ideología (populismo).

En muchos de los casos de las llamadas investigaciones cualitativas (etnográficas, investigación-acción, entre otras), estas usan a las comunidades para darle, vía consenso, legitimación a sus investigaciones. La validez que antes se hacía en los colegios o comunidades científicas (Lakatos), ahora en las mal llamadas ciencias populares (vía populismo), es llevado al seno de las comunidades, en donde hasta que no se logre la formación política y académica de la población, su participación será cuantitativa y no cualitativa, y lo que allí se haga como investigación podrá tener carácter socio-comunitario pero no científico. Algunos etnógrafos tratan a los grupos humanos a estudiar como si fueran objetos inertes, Goesty y LeCompte en Etnografía (1988), hablan de la educación y reconstrucción de escenas y grupos sociales intactos (énfasis del autor). 
Quizás la mayor contradicción de todas es que en el fondo deseamos cuestionar y hasta negar el papel de la ciencia por sus múltiples y evidentes deformaciones, pero en el fondo existe el miedo de alejarnos de ella y hasta por ego nos gusta etiquetarnos como científicos.

\section{5- Predominio de lo inductivo y lo descriptivo: no hay ciencia}

Frente a la crítica del método hipotético deductivo, al predominio de la racionalidad, la generalidad y ambigüedad de las leyes y teorías universales, ante la marginación de la vida cotidiana, hoy hay una revalorización de lo particular, lo individual, de lo micro social frente a lo macro social y "los megarelatos". Reconociendo la validez de esta posición es necesario advertir sobre los riesgos ya señalados de negar la historia de la ciencia, subestimar la teoría, sobrevalorizar al objeto de estudio y pretender que cada caso en particular responde a una verdad única, es decir; hay tantas verdades como casos particulares, donde cada investigación se legitima a sí misma, no hay contrastación ni debate científico, porque cada realidad particular investigada es verdad y se auto valida, esto niega la esencia misma de la razón humana, del desarrollo del hombre.

Los historiadores, por microcósmicos que sean, deben estar a favor del universalismo, no por lealtad a un ideal al que seguimos apegados muchos de nosotros, sino porque es la condición necesaria para comprender la historia de la humanidad, incluida la de cualquier sección especial de la humanidad. Porque todas las colectividades humanas son y han sido necesariamente parte de un mundo más amplio y más complejo. Una historia que esté concebida solo para los judíos (o los afroamericanos, o los griegos, o las mujeres, o los proletarios, o los homosexuales) no puede ser historia buena, aunque puede ser reconfortante para quienes la cultiven (Hobsbawm, 1998, p. 13).

Al final varios investigadores pudieran estar investigando un mismo tema pero con dificultad para establecer las comparaciones que permitan construir teorías. La teoría no puede responder solo a casos particulares, tiene una naturaleza (respetando el contexto) general y social. Asimismo la mayoría de las investigaciones autodenominadas como cualitativas no logran traspasar lo meramente descriptivo, enunciar elementos, cuantificar hechos y conductas con muy poca teoría y capacidad de generalización, es 
decir, en el fondo reproducen la perspectiva cuantitativa. Muchas de las interpretaciones que se hacen de la realidad, ante una efervescencia de lo subjetivo frente a lo tangible, cae más en el mundo de lo metafísico y la especulación vacía sin argumentos.

Para Martínez Miguelles: "la historia de la ciencia nos permite ver de manera palpable que sus avances más revolucionarios y significativos no provienen de investigaciones empíricas aisladas o de la acumulación de hechos y experimentos, sino de teorías novedosas inicialmente desconcertantes" (1999, p. 83).

Este autor critíca a Strauss y Corbin quienes sostienen "que la teoría se deriva inductivamente de los datos". También difiere de Goets y LeCompte por basarse en modelos y resolución de problemas, categorías más ligadas al funcionalismo y la administración que a la perspectiva cualitativa que dicen defender. Más adelante es aún más tajante en su apreciación sobre la formación de las teorías: "la teoría es por tanto, un modelo ideal, sin contenido observacional directo, que nos ofrece una estructura conceptual inteligible, sistemática y coherente para ordenar los fenómenos...” (p. 88) “...en síntesis, no tenemos técnicas de la construcción de teorías y no la tendremos nunca” (p. 90).

Uno de los autores más citados en la investigación-acción, John Elliott (2000), deja aún más claro que desde la acción y los casos particulares no se construye teoría científica, dejemos que sea el propio autor el que nos los explique: "los estudios de casos proporcionan una teoría de la situación, pero se trata de una teoría naturalista presentada de forma narrativa, en lugar de una teoría formal enunciada de forma proporcional” (p. 22).

Elliott cita a Gerbert Blumer sobre la diferencia de los conceptos definidoresobservadores y los sensibilizadores-orientadores, agregando la necesaria relación entre lo particular y lo general:

Al emplear los conceptos sensibilizadores nos hayamos entre la constante interacción entre lo particular y lo general. Solo puede comprenderse un caso concreto estudiando las características que tengan en común con otras situaciones y "paradójicamente" solo podemos entender lo que las situaciones 
tienen en común mediante el estudio de los casos particulares” (p. 28) (...) pienso que se puede elaborar teoría tanto desde el punto de vista de la ciencia como desde la práctica, y que el último consiste sobre todo en desarrollar nuestra comprensión de los conceptos de sentido común mediante el estudio de casos concretos" (p. 30).

Con estas citas pretendemos dejar explícito que puede ser válida y útil la investigación desde casos particulares y desde el conocimiento común, pero no son ciencia y eso lo tienen muy claro quienes le han dado existencias a estas posturas; no así muchos de sus supuestos defensores.

\section{6- Marginalización del entorno ético y sociopolítico}

Bajo nuestra perspectiva ontoepistemológica y ético política en el abordaje de la ciencia, no podemos dejar de nombrar lo que más que un riesgo o desviación pudiera ser intencionadamente planificado por quienes pregonan la defensa de lo cualitativo sobre lo cuantitativo, quienes en defensa de lo particular, lo subjetivo, el método inductivo, obvian el contexto político social, no solo del objeto o la comunidad concreta a estudiar sino del entorno y los procesos históricos, económicos, políticos y sociales que hacen entender esa realidad concreta dentro de una relación dialéctica con lo nacional y lo mundial.

Es una contradicción, y a nuestro modo de ver no espontáneo sino intencional, que en el contexto de la globalización y siendo nuestras ciencias criticadas por el disciplinarismo y su incapacidad de entender la totalidad y ante el llamado urgente que hace la posmodernidad por lo intra y transdisciplinario, el conocimiento científico, por el contrario, se fragmenta y se concretiza de tal manera que se convierte en un proceso administrativo y no sociopolítico.

Sin negar las críticas que se le ha hecho a la pretendida universalización de la ciencia y la tecnología atada a los intereses de las elites mundiales, no podemos negar una condición de la naturaleza humana que es su capacidad de generalizar y responder más allá que asuntos particulares, porque en el fondo eso que llamamos humanidad es una valoración y perspectiva éticas y política del hombre. 


\section{Historia ORAL: TEORÍAS Y FILOSOFÍA}

El historiador, su carácter de cientificidad, lo que lo hace distinto al cronista espontáneo, al hombre curioso, al relator de cuentos, es además del uso de las fuentes, escritas y orales, es su capacidad argumentativa, que no responde solamente a caprichos y pasiones -aunque estas últimas sean necesarias y fundamentales en el trabajo del historiador- sino que existe una coherencia y hay un dominio teórico y filosófico que hace ver a la historia mucho mas allá de una descripción de hechos aislados.

Sin bases teóricas y filosóficas -que no es simplemente citar algunos autores y referencias para el relleno y que en muchos trabajos o autodenominadas escuelas se reproducen y se multiplican por igual, en eso que llaman los metodólogos el marco teórico- no hay ciencia, no hay investigación, hay solamente recopilación de datos e información periodística, descripción etnográfica, que puede ser válida, interesante, útil, pero no es ciencia. Tampoco se trata de caer al contrario de aquellos, muy pocos por cierto, que solo se dedican a intentar construir teorías y filosofar sobre la historia pero que nunca han hecho investigación empírica, que no han ensuciado sus dedos en los polvorientos archivos ni han manifestado interés por el estudio de un proceso, un hecho, una localidad, unos personajes, sino solo recopilación de fuentes secundarias y especulación. Ambos, tanto el pragmático historiador como el creativo especulador y filósofo deben conjugarse.

La historia requiere de un campo de estudio particular, en este caso el tiempo histórico, que no es estático, que no puede ser parcelado y visto a través del microscopio, es un tiempo dinámico que se confunde con el presente, ya que es desde este donde partimos, vemos con los ojos del presente y es lógico que así sea, pero es necesario tener claro los peligros de interpretar el pasado con los modelos, categorías y teorías que privan en la actualidad. Pero la historia además requiere del conocimiento que producen las otras ciencias, porque siempre hacemos historia de la economía de la política, de la cultura, del espacio geográfico, es una historia de hombres, no de seres inanimados, metafísicos. La historia también debe tener un sentido, una filosofía orientadora y una axiología, que nos permita asumir una posición frente al mundo, no ser simples espectadores o narradores. 
Florez Malagón (2000), hace una fuerte crítica a las deficiencias ontoespistemológicas de la historiografía actual. Según su visión, no pasa de las simples generalidades sobre la modernidad y la posmodernidad, advirtiendo que este aislamiento teórico y filosófico no es reciente, que desde los griegos y quizás solo hasta el siglo XIX la historia fue mero relato, una descripción de hechos y es solo a partir de su institucionalización, a través de la enseñanza académica con los nuevos estados nacionales, que empieza a llamarse a sí misma ciencia: "tristemente las discusiones epistemológicas de los historiadores rara vez alcanzan un nivel alto, y las posiciones filosóficas rápidamente se reducen a posiciones políticas simples" (p. 29).

En una crítica a la corriente de las mentalidades de la Escuela de los Annales, señala que esta no representa realmente estudios culturales sino relatos culturales de orden descriptivo y subjetivo, señalando que es solo a partir de la década de los noventa del siglo pasado cuando esta visión comienza a producir algunos cambios.

Santana (2005), en una retrospectiva de la escuela de los anales señala los aportes significativos de estas corrientes, enfrentadas al positivismo y al historicismo, tanto en las síntesis históricas como la tendencia a la interdisciplinariedad, la sustitución de la historia relato por la historia problema. Reconoce este autor que los fundadores, Febvre y Bloch, se dedicaron fundamentalmente a un cambio en la visión metodológica de la historia estudiando las estructuras, coyunturas, las regiones históricas, implementando el concepto de civilización y así comparar distintas formaciones sociales, el concepto de historia total, la pluralidad temporal de Braudel.

Sin embargo, considera:

Que los fundadores de Annales conciben la renovación de la historia casi exclusivamente como una empresa metodológica y técnica, como una empresa que remite a la práctica investigadora más que a la elaboración de un cuerpo teórico alternativo al de la historia tradicional (p. 62).

Más adelante agrega: "el análisis social carece de una base conceptual sólida, pero es en el análisis económico donde las deficiencias son más patentes y donde la filiación política de la escuela se hace más nítida” (p. 63). 
Haciendo mención a lo que se ha denominado la tercera generación de los Annales: la historia de las mentalidades, que busca la valorización de lo subjetivo y de lo cultural, para este autor esta corriente representa un peligroso retorno a la historia narrativa, abandonando el análisis explicativo y la historia problema: "la historia de lo mental se reduce, por tanto, la más de las veces a la mera trascripción de las representaciones culturales al margen de cualquier relación con el contexto que las ha suscitado” (p. 72).

Sin embargo, Santana también reconoce que en los últimos años, sobre todo a partir de los sucesos políticos de 1989, con la caída del bloque socialista, ha surgido una cuarta generación de los Annales que intenta rescatar algunos de los principios fundamentales de esta corriente y cubrir las deficiencias señaladas en el plano de lo teórico y lo filosófico.

Para Roch Little (2000), la historiografía actual no ha logrado, en la mayoría de los casos, romper con la visión historicista y positivista de convertir al pasado en un objeto inmóvil, presa fácil del historiador que teniendo un objeto de estudio pueda autocalificarse de científico. Seńala este autor, que en realidad lo que ha sucedido desde Ranke hasta nuestros días es una arbitraria manipulación del pasado, que más que develar la historia tal como fue, describe la historia tal como la quiso el historiador. El pasado se convierte así en una especie de diversión que satisface las necesidades de algunos hombres curiosos, o en el peor de los casos de aquellos que por intereses políticos pretenden manipular el pasado a su antojo. La crítica es una historia fundamentalmente política llena de nacionalismos, pasiones, hecha por personas que escudriñan en papeles y archivos viejos y estos en forma casi mágica le revelan sus verdades. El pasado se ha convertido, según esta visión, en "la víctima de los historiadores" de aquellos que solo pretenden legitimar el presente utilizando el pasado.

La fuente oral parte de una teoría y filosofía, parte de entender que la fuente escrita no es suficiente, que ha sido el producto de intereses de los sectores dominantes, que los documentos en la mayoría de los casos representan una síntesis, muchas veces marcadamente esquemática que solo aborda transacciones económicas o descripciones de contiendas políticas.

La etnografía, hermenéutica, historias de vida, fenomenología, entre otras corrientes, buscan rescatar lo sensible, lo humano, lo subjetivo, las pasiones, lo familiar, lo personal, 
que muy poco aparece reflejado en los documentos, estos son temas de la fuente oral. Pero sus propósitos encierran una filosofía, una intencionalidad del historiador, que a su vez se arma de las teorías para poder descifrar las categorías, conceptos que le proporcionan los entrevistados. Toda esa información que le permite al historiador contextualizar más allá del sujeto investigado y entrevistado.

Al decir de Marc Bloch:

En una palabra, un fenómeno histórico nunca puede ser explicado en su totalidad fuera del estudio de su momento. Esto es cierto de todas las etapas de la evolución. De la etapa en que vivimos como de todas las demás. Ya lo dijo el proverbio árabe: "los hombres se parecen más a su tiempo que a sus padres" (1996, p. 30).

En este mismo orden de ideas, Pierre Vilar advierte:

La investigación histórica es el estudio de los mecanismos que vinculan la dinámica de las estructuras -es decir, las modificaciones espontáneas de los hechos sociales de masas- a la sucesión de los acontecimientos en los que intervienen los individuos y el azar, pero con una eficacia que depende siempre, a más o menos largo plazo, de la educación entre estos impactos discontinuos y las tendencia de los hechos de masas (1980, p. 47).

El historiador debe responder a preguntas como: ¿qué ha estado sucediendo en el mismo espacio geográfico estudiado?, ¿cuál es el contexto nacional e internacional en el que ocurrieron los hechos?, ¿es este un caso único? Además de la contextualización la triangulación de las fuentes nos permite comprobar, demostrar hasta qué punto es cierto lo dicho por los entrevistados, o si es una invención.

Lucien Febvre (1992), en Combates por la Historia, nos señala que: "el hombre aislado es una abstracción. La realidad del hombre es en grupo. Y el hombre no conserva en su memoria el pasado de la misma forma en que los hielos del Norte conservan congelados los mamuts" (p. 32). 
Toda historia es una reconstrucción e interpretación desde el presente, el historiador no entra al pasado como quien busca una ajuga en un pajar, la historia es un océano y el historiador traza un curso de navegación, de lo contrario se pierde en la inmensidad, se ahoga en el mar de datos e información. Para Febvre es necesario problematizar la historia: "en una historia sin problematizar no hay historia" (p. 42).

Para el historiador francés:

Es preciso que la historia deje de aparecer como una necrópolis dormida por la que pasan sombras despojadas de sustancia. Es preciso que penetréis en el viejo palacio silencioso donde la historia duerme, animados por la lucha, cubiertos del polvo del combate (p. 57).

Con respecto a los métodos, señala que son una herencia del pasado, que tienen validez, pero que no es suficiente con que el historiador sepa utilizarlos.

Debe bañarse en la vida, con la sensación de que sumergiéndose en ella, bañándose en ella, penetrándose en ella de humanidad presente, despliega sus fuerzas de investigación, su potencia de resurrección del pasado. De un pasado que detenta y que restituye, en intercambio, en secreto sentido de los humanos (p. 71).

\section{LA HISTORIA ORAL: TESTIMONIOS Y LOS VAIVENES DE LA MEMORIA}

En las entrevistas orales, el testimonio puede ser fuente e instrumento para el trabajo del periodista, narrador, analista de discurso, el politólogo, el sicólogo, biógrafo, cultor, antropólogo y también del historiador. Lo que hace que una entrevista se convierta en fuente para la reconstrucción histórica es el historiador, mejor dicho la persona con conocimientos profundos sobre los siguientes elementos: 1) Contextualización del sujeto que investiga. 2) Contextualización del tiempo que se pretender abordar. 3) Conciencia, es decir, dominio teórico y filosófico que le permiten entender el sentir de la fuente oral. 4) Capacidad de triangular la información de la fuente oral con la fuente escrita. 5) Capacidad de sintetizar y narrar con el discurso histórico esta conjugación de información, teorías y filosofías. 
Entre los criterios para las fuentes orales está el de entrevistar a otros sujetos que hayan vivido o conozcan sobre lo estudiado, es una forma de contrastar, analizar las similitudes y diferencias en las informaciones dadas y confrontarlas con los documentos escritos. Las fuentes orales también responden a un tiempo histórico determinado, es decir, la memoria no puede superar más de dos o tres generaciones anteriores. Una persona puede hablar con propiedad de sus padres y sus abuelos más allá de eso, de ese tiempo se hacen cuesta arriba, y tiende a surgir más la fantasía y los deseos que la verdad histórica.

La mayoría de historiadores coinciden en señalar que la fuente oral no puede abarcar más de 150 años. Por ejemplo en nuestra historia venezolana hemos visto cómo se confunden, en esta historia oral, sucesos de la Guerra de Independencia (1810-1821) con los sucesos de la Guerra Federal (1859-1863). Otros ejemplos los hemos visto al pretender reivindicar nuestros ancestros aborígenes desde la historia oral. Tratar de reconstruir en la memoria procesos de 500 años, que no tienen asideros ni en las fuentes documentales ni en los registros antropológicos.

A la hora de analizar testimonios, conviene que el historiador saque provecho de la psicología del testimonio. O lo que es lo mismo, tener presente que las personas se equivocan a la hora de ubicar tanto el espacio como el tiempo. El mismo estado físico del testigo puede hacer que las cosas se vean y escuchen de una u otra forma, o los prejuicios de la época, o situaciones de convulsión colectiva. Se debe tener en cuenta que los testimonios no son propiamente sino la expresión de recuerdos. De todos modos, estas afirmaciones en apariencia pesimistas no afectan a la estructura elemental del pasado (Bloch, 1996).

La historia no es una regresión psicoanalítica ni tampoco un viaje al pasado, a ambos estamos inhabilitados. El pasado es, por definición, un dato que ya nadie habrá de modificar (Ibídem). La historia es una construcción desde el presente, es siempre una interpretación, es básicamente argumentativa y discursiva. No es neutra ni objetiva, la práctica historiográfica no es realizada por hombres descarnados, no son sujetos acontextuales, son siempre hombres con posiciones ideológicas y políticas con intereses particulares. 
Tal como lo plantea Edwar H. Carr (1993):

Los hechos de la historia nunca nos llegan en estado puro... siempre hay una refracción al pasar por la mente de quien los recoge. De ahí que cuando llega a nuestras manos un libro de historia, nuestro primer interés debe ir al historiador que lo escribió y no a los datos que contiene (p. 74).

Compartimos con Dora Schwarzstein para quien no puede confundirse historia oral con testimonios, ni tampoco hacer del testimonio un simple registro:

Por el contrario, se trata de productos culturales complejos. Incluyen interrelaciones cuya naturaleza no es fácil de comprender, entre memorias privadas, individuales y públicas, entre experiencias pasadas, situaciones presentes y representaciones culturales del pasado y el presente. En otras palabras, los testimonios de historia oral están profundamente influidos por discursos y prácticas del presente y pertenecen a la esfera de la subjetividad (1991, p. 133).

Más adelante, insiste en lo complejo que es abordar un testimonio y las formas en que se construye y constituye la memoria como fuente de la historia, cuyo tratamiento no puede ser ingenuo y requiere de habilidades y dominio teórico: filosófico del historiador:

El testimonio, cuya materia prima es la memoria, no es la historia. Por tanto, no es suficiente recuperar la memoria y transmitirla, sino que es imprescindible reflexionar sobre su naturaleza para poder entenderla, analizarla e incorporarla plenamente a la narrativa histórica. Esa es la única manera de transformar la memoria en historia. (...) No se trata entonces de la mera búsqueda de nuevas fuentes para una nueva historia, es necesario entender los mecanismos a través de los cuales el testimonio se construye y constituye. Esta precaución elimina toda ilusión de transparencia del discurso de los sujetos. Las entrevistas no nos acercan a la historia instantánea, no son "la voz del pasado", ni la memoria es una fotografía inmaculada de los hechos que ocurrieron. Lo que implicaría adherir a una visión empirista e ingenua frente a la cual es necesario estar alerta (p. 80). 
El fundador de los Annales, Marc Bloch, nos refiere a las imposturas al tratar los testimonios:

La impostura es capaz de viciar un testimonio. Esta a su vez puede tomar dos formas. Primero es el engaño acerca del autor y de la fecha: la falsedad, en el sentido jurídico de la palabra. Existe una forma más insidiosa del engaño; en vez de la mentira brutal, completa y, si puede decirse, franca, el solapado retoque: interpolaciones en cartas auténticas, o el bordado en las narraciones, sobre un fondo aproximadamente verídico, de detalles inventados. Eminentemente variable, de un individuo a individuo, la facultad de observación no es, tampoco, una constante social. Sin embargo, para que el error de un testigo venga a ser el de muchos hombres, para que una observación equivocada se metamorfosee en falso rumor, es necesario que el estado de la sociedad favorezca esa difusión (pp. 44-45).

El maestro francés refiere a que la crítica del testimonio, que trabaja sobre realidades psíquicas, será siempre un arte lleno de sutilezas. Para ella no existe libro de recetas. La crítica se mueve entre dos extremos: la similitud que justifica y la que desacredita. En cuanto al abordaje metodológico de los testimonios insiste sobre la importancia del método comparativo, el conocimiento de la psicología humana y al carácter "detectivesco" que debe asumir el historiador:

Para que un testimonio sea reconocido como auténtico hemos visto que el método exige que presente una cierta similitud con los testimonios vecinos. La crítica se basa sobre el trabajo de la comparación. No se podrá fechar un objeto ni pronunciarse sobre su autenticidad si no es posible relacionarlo con huellas ajenas al hombre. Los vestigios se tienen que poder insertar en una tabla cronológica o en un conjunto sincrónico. La concordancia de un testimonio con los testimonios cercanos establecerá unos tipos de conclusiones u otros. Son tan sospechosos dos relatos sobre el mismo suceso completamente distintos como otros dos completamente iguales. En el caso de relatos distintos, está claro que alguno no dice la verdad. Investigar las razones que llevaron a componerlos de esa forma, utilizar el análisis psicológico, hará que se encuentre al probable impostor, como también el comprobar si concuerda 
con otros documentos de la misma época en cuanto a su morfología. Uno de los dos tiene que sucumbir: el principio de contradicción prohíbe inexorablemente que un acontecimiento pueda a la vez ser y no ser. Por lo que respecta a dos documentos exactamente iguales, si dos testigos narran el mismo acontecimiento con las mismas palabras, los mismos detalles, está prácticamente claro que uno de los dos copió al otro o que ambos copiaron un modelo común. No resulta demasiado razonable que dos narradores utilicen exactamente las mismas palabras, como tampoco que ambos vieran y oyeran exactamente lo mismo situados en espacios distintos y con distinta capacidad de atención. La crítica se mueve entre dos extremos: la similitud que justifica y la que desacredita (Bloch, 1996, p. 47).

El historiador Peter Burke nos insiste en la necesidad de problematizar la memoria como fuente historiográfica, de rehuir de la visión ingenua de confundir la memoria con verdad histórica:

La visión tradicional de la relación entre memoria e historia escrita, en la que la memoria refleja lo que ocurrió realmente y la historia refleja la memoria, actualmente resulta demasiado simple. Tanto la historia como la memoria parecen cada vez más problemáticas. Recordar el pasado y escribir sobre él ya no se consideran actividades inocentes. $\mathrm{Ni}$ los recuerdos ni las historias parecen ya objetivos. En ambos casos los historiadores están aprendiendo a tener en cuenta la selección consciente o inconsciente, la interpretación y la deformación (2000, p. 207).

Según Burke, el primer explorador serio del "marco social de la memoria", fue en los años veinte el sociólogo o antropólogo francés Maurice Halbwachs, pero fue, según él, a inició de los años sesenta cuando los historiadores del siglo XX se dieron cuenta de la importancia de la "historia oral". Halbwachs argumentaba que los grupos sociales construyen los recuerdos. Son los individuos los que recuerdan en sentido literal, físico, pero son los grupos sociales los que determinan lo que es "memorable" y cómo será recordado. Los individuos se identifican con los acontecimientos públicos importantes para su grupo. 
Pero Burke advierte sobre los peligros de tomar términos de la psicología individual y simplemente añadirles el adjetivo "colectivo" (como en los casos de représentations collectives, mentalités collectives, conscience collective y mémoire collectivé) (p. 209). En esta misma tónica, para Mauricio Ochoa, Halbwachs habría partido del concepto de "conciencia colectiva" de Durkheim, desde el cual sostiene que:

La memoria es siempre una construcción social, lo cual plantea una distinción entre memoria individual y memoria colectiva. En tanto, no puede ser considerada exclusivamente una facultad individual ya que los individuos pueden recordar debido precisamente a su pertenencia a un grupo social (2005, p. 5).

Ochoa nos dice que "la memoria no recuerda las cosas tal y como fueron, sino que es una reconstrucción del pasado desde el presente que modula, recrea, olvida e interpreta, de diversos modos, el pasado" (2005, p. 9).

Desde hace mucho tiempo la psicología y también la sociología se han dedicado a estudiar los secretos y misterios de la memoria individual y colectiva. Desde experimentos cuya finalidad era identificar las leyes que rigen la memoria, que sirvieron de base al surgimiento de la neurociencia. Según Ochoa:

La memoria la podemos entender en la actualidad como un proceso cognitivo mediante el cual las neuronas hacen sinapsis para dar como resultado el almacenamiento de información que podrá ser luego evocada, es decir, permitir traer eventos del pasado al presente. Los mecanismos relacionados con la búsqueda de información almacenada gracias a la educación formal e informal y la experiencia acumulada a lo largo de la vida constituyen la memoria (2005, p. 8).

$\mathrm{Al}$ respecto, Ochoa indica lo siguiente:

La actividad cerebral no es paralela a la realidad, en el sentido de que el cerebro procesa la información de manera discontinua, pero la realidad, como el tiempo son continuos, esto nos hace entender, en primera medida, que el 
cerebro nuestro lo que hace es captar de manera fragmentada la realidad y esto se realiza por un proceso cognitivo que se llama atención, por lo tanto el cerebro lo que hace es seleccionar lo emotivamente importante para nosotros y después ver si debe ser guardado como memoria o simplemente desecharlo, así pues para registrar alguna información debe pasar con anterioridad por nuestra atención y nuestra emoción (p. 12).

Dora Schwarzstein nos advierte sobre las diferencias que existen entre el tiempo histórico y los tiempos biográficos a los que nos llevan los testimonios basados en la memoria:

Las narrativas se estructuran en torno a tiempos diferentes, no siguen en general una cronología ordenada. El tiempo biográfico, representado por momentos claves del ciclo de vida individual, se impone en casi todos los casos al tiempo histórico. La percepción del tiempo está marcada por dos polos, la nostalgia del pasado y el tiempo futuro, encarnado en la ilusión del retorno. Sin embargo, todas las narrativas están construidas desde el presente y es esa presencia la que las estructura. Si bien los hechos históricos del pasado aparecen en las entrevistas y van marcando ciclos, no parecen ofrecer una estructura conveniente para marcar el tiempo individual o de la comunidad (op. cit., p. 81).

Esto nos lleva a Marc Bloch cuando nos señala que "el camino natural de toda investigación es el que va de lo mejor conocido a lo más oscuro", sin responder a una cronología exacta de los hechos, sino en razón a los intereses particulares y a la forma de problematización del investigador.

Para Burke, la memoria es maleable y debemos entender cómo se modela y por quién, así como los límites de su maleabilidad. También debemos tener presente algo que los historiadores a veces han olvidado, la advertencia de un perceptivo crítico literario: "Cuando leemos escritos dictados por la memoria, es fácil olvidar que no estamos ante la propia memoria, sino ante su transformación mediante la escritura” (p. 70).

Según Burke, para comprender el funcionamiento de la memoria colectiva quizá convenga investigar la organización social del olvido, las normas de exclusión, supresión 
o represión, y la cuestión de quién quiere que alguien olvide qué y por qué. "Como este es el opuesto complementario del concepto "memoria colectiva", en adelante la denominaré "amnesia colectiva". ¿Pueden los grupos, como los individuos, suprimir lo que no conviene recordar? Y, si es así, ¿cómo lo hacen?” (p. 81).

A todo esto tiene que dedicarse el historiador y no solo a transcribir testimonios. Tal como lo plantea Ochoa, el análisis de la memoria es una herramienta para develar los usos políticos del pasado por parte de los productores de memoria, quienes para tales efectos pueden recurrir a la recreación y a la invención histórica.

\section{A Manera de CONCLUSIÓN}

No hemos pretendido negar el papel de las fuentes orales ni mucho menos la importancia de la historia popular. Sino, por el contrario, partiendo por revalorizar y reconocer las fuentes orales como tan legitimas como las fuentes escritas, su papel en el rescate de lo subjetivo y de la memoria colectiva, nos oponemos a quienes hacen mal uso de ellas, advertimos sobre su banalización, el desconocimiento que existe sobre teorías, metodologías y paradigmas filosóficos que sustentan y dan basamento a la historia del pueblo y al uso de las fuentes orales.

Compartimos plenamente con quienes han hecho esfuerzos para reconstruir la historia de sectores marginados de la historia tradicional, los excluidos, pero esto no nos puede llevar a legitimar a una historia manipuladora y populista, engańosa, cargada de buenos deseos pero fantasiosa, historia reduccionista y mitológica, una historia carente de fuentes, débil en teoría, método y filosofía, que hace de la ciencia histórica cualquier cosa y del historiador un vulgar charlatán. Confrontaremos por igual a este tipo de historia como lo hemos hecho con la historia tradicional. 


\section{REFERENCIAS}

Barbero, J. (2002). La educación desde la comunicación. En Tecnologias de Información y Comunicaciones para enseñanza básica y media. Buenos Aires: Editorial Norma.

Bermúdez, N. y Rodríguez, M. (2009). Fuente oral en la reconstrucción de la memoria histórica: aporte al documental "Memorias de Zulia Petrolero". Revista de Ciencias Sociales, 15(2), [citado 2012-10-25], pp. 317-328.

Bloch, M. (1981). Introducción a la Historia. México: FCE.

(1996). Aapología para la historia o el oficio de historiador. México D.F: Fondo de Cultura Económica.

Burke, P. (2000). Formas de historia cultural. Madrid: Editorial Alianza.

Carr, E. (1993). ¿Qué es la Historia? Buenos Aires: Editorial Planeta.

Dussel, E. (2001). Hacia una filosofía política crítica. Bilbao, España: Editorial Desclée de Brouwer S.A.

Elliott, J. (2000). La investigación acción en la educación. Madrid: Ediciones Moritz.

Fals, O. (1992). La ciencia y el pueblo: nuevas reflexiones. En La investigación-acción participativa. Colombia: Editorial Popular.

Febvre, L. (1992). Combates por la historia. Barcelona: Ariel.

Florez, A. (2000). La Historia en su encerramiento: una mirada iconoclástica al quehacer de la historia en Colombia. En Fronteras de la Historia. Instituto Colombiano de Antropología e Historia, 5. Bogotá, Colombia.

Fraser, R. (1993). La historia oral como historia desde abajo. Revista Ayer, (12), 79-92. 
Freire, P. (1977). La educación como práctica de la libertad. México: Siglo XXI Editores. (1991). Pedagogía de los oprimidos. Caracas: Siglo XXI Editores.

García, N. (1990). Culturas Hibridas. México D.F: Editorial Grijalbo.

González, M. (2012). La historia oral: nuevas fuentes para comprender nuestro pasado. Disponible en http://perceianadigital.com/index.php/geografia-e-historia/1142-lahistoria-oral-nuevas-fuentes-para-comprender-nuestro-pasado

Habermas, J. (1990). Teoría y Praxis. Madrid: Editorial Tecnos.

Hobsbawm, E. (1998). La historia de la identidad no es suficiente. En Sobre la Historia Critica. Barcelona: Grijalbo.

Levinas, E. (2002). Algunas reflexiones sobre las Filosofias del Hitlerismo. Argentina: Fondo de Cultura Económica.

Landreani, N. (1990). Métodos cuantitativos vs. Métodos cualitativos: un falso dilema. En Revista Ciencia, Docencia y Tecnología, (1). Caracas: Unesr.

Mafesoli, M. (1993). El Conocimiento Ordinario. México: Fondo de Cultura Económica.

Martínez, M. (1999). La Investigación cualitativa etnográfica en educación. Madrid: Editorial Trillas.

Roch, L. (2000). La miseria de la historia cientificista: Reflexiones y prácticas del conocimiento histórico. En Fronteras de la Historia. Instituto Colombiano de Antropología e Historia, 5. Bogotá.

Santana, J. (2005). Paradigmas historiográficos contemporáneos. Venezuela: Fundación Buría. 
Schwarzstein, D. (org.). (1991). La historia oral. Buenos Aires: Centro Editor de América Latina.

Valderrama, T. (2000). El vuelo de la mariposa amarilla. Caracas: Editorial Esperanza.

Vargas, I. (1999). Las pequeñas cosas olvidadas de la cultura popular. En Tradición en la Modernidad. Caracas: Edición USB-Fundación Bigott.

Vilar, P. (1980). Iniciación al vocabulario del análisis histórico. Barcelona: Editorial Crítica. 